\title{
PENGELOLAAN OBAT PROLANIS PASIEN BPJS KESEHATAN DI APOTEK SANA FARMA MAKASSAR PADA PERIODE TAHUN 2018-2019
}

Drug Management Of Chronic Disease Management Program Of Healthcare BPJS Patients In Sana Farma Pharmacy In Makassar From 2018 To 2019

\author{
Veronica MD ${ }^{1}$, Rusli ${ }^{2}$, Noer Widya Ningsih ${ }^{1}$ \\ ${ }^{1}$ Stikes Pelamonia Kesdam VII/Wrb \\ ${ }^{2}$ Jurusan Farmasi Poltekkes Kemenkes Makassar
}

*Email: veronicamd99@yahoo.com

DOI: https://doi.org/10.32382/mf.v15i2.1129

\begin{abstract}
The drug management system is a series of activities carried out, such as planning, procurement, receipt, storage, distribution, control/reporting, and annihilation. The purpose of this study was to examine the supervision of drugs, especially in the Chronic Disease Management Program of healthcare BPJS patients in Sana Farma Pharmacy in Makassar. The research method used was descriptive qualitative, which was to obtain data from interviews and direct observation to analyze the drug management in the period 2018-2019. The respondents involved in this study were Pharmacists, the Manager (APJ), the Facility Owner (PSA), Technical Staff (TTK), and warehouse officers who were willing to respond to interview questions. The results of this study indicate that the drug management of the Chronic Disease Management Program has fulfilled SOP in Sana Farma Pharmacy in Makassar. The analysis of drug management in the period 2018-2019 shows that the drugs included in the planning of 2018-2019 were of the same amount and type. Drug storage based on the FEFO and FIFO system as well as temperature regulation. Also, the drug distribution met the standards set by BPJS and SOP of Sana Farma Pharmacy. The process of drug control is carried out in minutes of the destruction and verification of recipes according to the applicable regulations.
\end{abstract}

Keywords: Analysis, Drug of Chronic Disease Management Program, Management of Sana Farma Pharmacy

\section{ABSTRAK}

Sistem pengelolaan obat merupakan suatu rangkaian kegiatan yang dilakukan seperti perencanaan,pengadaan, penerimaan, penyimpanan,pendistribusian, pengendalian/pelaporan dan pemusnahan. Tujuan penelitian ini untuk mengetahui tentang pengelolaan obat khususnya pada obat Prolanis pasein BPJS DI Apotek Sana Farma Makassar.Metode penelitian yang digunakan adalah kualitatif deskriptif untuk mendapatkan data dari hasil wawancara dan observasi langsung untuk menganalisis pengelolaan obat Prolanis pasien BPJS Kesehatan di Apotek Sana Farma Makassar pada periode tahun 2018-2019. Responden yang terlibat dalam penelitian ini adalahApoteker, APJ, PSA, TTK dan petugas gudang di Apotek Sana Farma Makassar yang bersedia menjawab lembar wawancara. Hasil dari penelitian ini menunjukkan bahwa pengelolaan obat Prolanis telah memenuhhi SOP di Apotek Sana Farma Makassar.Analisis pengelolaan obat Prolanis pasien BPJS Kesehatan di Apotek Sana Farma Makassar pada periode tahun 2018-2019 menunjukkan bahwa obat yang masuk dalam perencanaan ditahun 2018-2019 jumlah dan jenisnya hampir sama, dalam memenuhi pengadaan obat Prolanis tergantung dari pembayaran BPJS yang telah di sepakati. Dalam penyimpanan obat Prolanis berdasarkan sistem FEFO dan FIFO serta pengaturan suhu.Proses pendistribusian obat Prolanis sudah memenuhi standar yang telah ditetapkan oleh BPJS dan SOP Apotek Sana Farma Makassar.Proses pengendalian obat Prolanis di Apotek Sana Farma Makassar dilakukan berita acara pemusnahan dan verifikasi resep dari pihak BPJS. Dalam proses pemusnahan di Apotek Sana Farma Makassar dilakukan sesuai dengan aturan yang berlaku.

Kata Kunci : Analisis, Obat Prolanis, Pengelolaan Apotek Sana Farma 


\section{PENDAHULUAN}

Kesehatan merupakan hak azasi manusia. Setiap orang mempunyai hak untuk hidup layak, baik dalam kesehatan pribadi maupun keluarganya termaksud didalamnya mendapatkan makanan, pakaian, perumahan, dan pelayanan kesehatan serta pelayanan sosial lain yang diperlukan (Atmini, GandjaR, \& Purnomo, 2011).

Kesehatan merupakan hal yang utama bagi manusia. Setiap individu dapat melakukan aktivitas sehari-hari dengan produktif dengan keadaan yang sehat. Saat sakit tentu diperlukan biaya untuk berobat ke dokter atau membeli obat.Pemerintah Indonesia bertanggung jawab dalam memberikan jaminan perlindungan kesehatan dan fasilitas bagi masyarakat Indonesia sesuai dengan Peraturan Presiden Nomor 28 Tahun 2016 mengenai Jaminan Kesehatan (Putri \& Kartika, 2017).

Setiap orang berhak atas jaminan sosial untuk dapat memenuhi kebutuhan dasar hidup yang layak dan meningkatkan martabatnya menuju terwujudnya masyarakat Indonesia yang sejahtera, adil, dan makmur.Oleh karenanya Pemerintah menerbitkan Undang-undang nomor 40 tahun 2004 tentang Sistem Jaminan Sosial Nasional (SJSN).Semenjak 1 Januari 2014, Jaminan kesehatan menjadi implementasi jaminan pertama dari penyelenggaraan jaminan sosial. Kesehatan merupakan hal yang krusial bagi setiap makhluk.Dalam penyelenggaraan jaminan kesehatan maka dibentuklah Badan Penyelenggara Jaminan Sosial (BPJS) Kesehatan sebagaimana yang diatur dalam Undang-undang nomor 24 tahun 2011 (Edris \& Lusianti, 2016).

Penyakit kronis merupakan permasalahan kesehatan serius dan penyebab kematian terbesar di dunia.Pada tahun 2008, penyakit kronis menyebabkan kematian pada 36 juta orang di seluruh dunia atau setara dengan $36 \%$ jumlah kematian di dunia.Berdasarkan hasil temuan Riskesdas pada tahun 2013, penyakit kronis merupakan salah satu penyebab utama kematian di Indonesia.Sejak tahun 2014 BPJS Kesehatan telah menerapkan Program Pengelolaan Penyakit kronis (Prolanis) (Rosdiana \& Rahardjo, 2017).

Standar pelayanan obat kronis oleh BPJS kesehatan memiliki program unggulan yaitu Program Rujuk Balik (PRB) yang bertujuan untuk meningkatkan kualitas pelayanan kesehatan bagi peserta dan memudahkan akses pelayanan kesehatan kepeda peserta penderita penyakit kronis. Terdapat sembilan penyakit kronis yang termaksud dalam program rujuk balik yaitu penyakit diabetes melitus, hipertensi, jantung, asma, Penyakit paru Obstruktif Kronis
(PPOK), epilepsi, stroke, schizoprenia, Systemic Lupus Eryhematosus (SLE). Program Rujuk Balik ditujukan bagi penderita sembilan penyakit tersebut dengan kondisi sudah terkontrol/stabil namun masih membutuhkan pengobatan atau asuhan keperawatan dalam jangka panjang. Peserta memperoleh obat program rujuk balik di Apotek/depo farmasi yang bekerjasama dengan BPJS Kesehatan. Terjadi peningkatan pelayanan obat bagi peserta program rujuk balik pada setiap bulannya. Apabila jumlah permintaan atau kebutuhan lebih besar daripada tingkat persediaan yang ada, maka akan terjadi kekurangan persediaan atau biasa disebut dengan stock out (kekosongan) obat yang menjadi perhatian bagi Apotek dan Khususnya bagi BPJS Kesehatan. Kekosongan obat di Apotek berkaitan erat dengan pengelolaan obat. Pengelolaan obat merupakan salah satu kegiatan yang mencakup perencanaan, pengadaan, penerimaan, penyimpanan, pendisribusian/pengendalian dan pemusnahan (Lanathasya \& Nadjib, 2015).

Pelayanan kefarmasian telah mengalami perubahan yang semula hanya kepada pengelolaan obat (drug oriented) berkembang menjadi pelayanan komprehensif meliputi pelayanan obat dan pelayanan farmasi klinik yang bertujuan untuk meningkatkan kualitas hidup pasien. Praktik kefarmasian dilakukan berdasarkan standar pelayanan kefarmasian diapotek, yang ditetapkan sebagai acuan pelaksanaan pelayanan kefarmasian diapotek (Mulyagustina, Wiedyaningsih, \& Kristina, 2017).

Obat merupakan komponen penting yang ketersediaannya berpengaruh dalam keberhasilan penyelenggaraan upaya kesehatan. Sejak era otonomi daerah kewajiban penyediaan dan pengelolaan obat publik untuk wilayah kabupaten/kota merupakan kewajiban pemerintah daerah (Kusmini, Satibi, \& Suryawati, 2016).

Apotek Sana Farma merupakan salah satu apotek yang melayani pengambilan obat Prolanis pasien BPJS.Oleh karena itu peneliti ingin mengetahui cara pengelolaan obat Prolanis pasien BPJS.

\section{METODE}

Analisis pengelolaan obat prolanis pasien BPJS kesehatan termasuk penelitian kualitatif yang disajikan secara deskriptif berupa kata-kata tertulis atau lisan dari perilaku responden yang diamati yang bertujuan untuk mendapatkan informasi yang lebih mendalam tentang pengelolaan obat prolanis pasien BPJS pada tahap perencanaan, pengadaan, 
penerimaan, penyimpanan, pendistribusian, pengendalian/pelaporan dan pemusnahan dan menggunakan metode analisis ABC.

\section{HASIL}

Dari hasil analisis $\mathrm{ABC}$ menunjukkan bahwa obat Prolanis BPJS yang telah diolah berdasarkan Analisis ABC, sebanyak 218.998 obat $(63,97 \%)$ masuk kategori A, sebanyak 86.939 obat $(25,39 \%)$ masuk kategori B, sebanyak 36.377 obat $(10,62 \%)$ masuk kategori C.

Dari hasil analisis $\mathrm{ABC}$ menunjukkan bahwa obat Prolanis BPJS yang telah diolah berdasarkan Analisis ABC, sebanyak 216.312 obat $(64,41 \%)$ masuk kategori A, sebanyak 84.653 obat $(25,21 \%)$ masuk kategori B, sebanyak 34.807 obat $(10,36 \%)$ masuk kategori C.

Perencanaan obat Prolanis BPJS di Apotek Sana Farma Makassar dilakukan sesuai SOP. Pengadaan obat Prolanis belum memenuhi kebutuhan karena dana yang diberikan oleh BPJS tidak mencukupi(lihat lampiran). Proses penerimaan Obat Prolanis BPJS di Apotek Sana Farmasering terjadi kendala pada saat penerimaan barang karena kurangnya tenaga kefarmasian dan kurang meneliti dalam penerimaan barang. Penyimpanan Obat Prolanis BPJS tidak terjadi kendala karena dilakukan sesuai SOP. Pendistribusian Obat Prolanis BPJStidakterjadi kendala karena dilakukan sesuai SOP dan obat Prolanis di Apotek Sana Farma semuanya terdistribusikan. Pengendalian/Pelaporan Obat Prolanis BPJS tidakterjadi kendala karena dilakukan sesuai SOP. Pemusnahan Obat Prolanis BPJS tidakterjadi kendala karena dilakukan sesuai SOP.

Tabel 1. Analisis ABC Pemakaian Obat Tahun 2018.

\begin{tabular}{lccc}
\hline No & Kategori & $\begin{array}{c}\text { Jumlah } \\
\text { Obat }\end{array}$ & Presentase \\
\hline 1. & A & 218.998 & $63,97 \%$ \\
2. & B & 86.939 & $25,39 \%$ \\
3. & C & 36.377 & $10,62 \%$ \\
& Jumlah & $342.317,58$ & $100 \%$ \\
\hline
\end{tabular}

Rumus : Pemakaian kumulatif Jumlah Total Rata2/Bulan X 100

Tabel 2. Analisis ABC Pemakaian Obat Tahun 2019.

\begin{tabular}{cccc}
\hline No. & Kategori & $\begin{array}{c}\text { Jumlah } \\
\text { Obat }\end{array}$ & Presentase \\
\hline 1. & A & 216.312 & $64,41 \%$ \\
2. & B & 84.653 & $25,21 \%$ \\
3. & C & 34.807 & $10,36 \%$ \\
Jumlah Total & $335.790,00$ & $100 \%$ \\
\hline
\end{tabular}

\section{Rumus : Pemakaian kumulatif Jumlah Total Rata2/Bulan

\section{PEMBAHASAN}

Hasil analisis data ini menggambarkan tentang keseluruhan dari informasi yang diperoleh selama proses penelitian dilakukan, hasil yang terbentuk disusun berdasarkan tujuan penelitian ditambah dengan informasi-informasi yang menjadi temuan peneliti selama penelitian berlangsung. Kegiatan yang dilaksanakan dalam upaya menganalisis Pengelolaan obat Prolanis pasien BPJS Kesehatan di Apotek Sana Farma Makassar.

Apotek Sana Farma Makassar melakukan perencanaan obat Prolanis dengan melihat stok obat digudang kemudian melakukan inventarisir/pencatatan stok obat dan melihat daftar pesanan obat yang banyak dipesan. Tujuannya agar dapat meningkatkan efektivitas dan juga efisiensi pengelolaan obat Prolanis Pasien BPJS mulai dari perencanaan, pengadaan, penerimaan, penyimpanan, pendistribusian, pengendalian/pelaporan dan pemusnahan obat yang merupakan daftar obat terpilih yang dibutuhkan pasien Prolanis dan tersedia difasilitas pelayanan BPJS. Tujuan utama peraturan obat daftar Addendum pertama Formularium Nasional adalah untuk meningkatkan mutu pelayanan kesehatan, melalui peningkatan efektivitas dan efisiensi pengobatan sehingga tercapai penggunaan obat yang rasional. Bagi tenaga kesehatan, daftar Addendum pertama Formularium Nasional bermanfaat bagi "acuan" bagi penulis resep, mengoptimalkan bagi pelayanan kepada pasien Prolanis, memudahkan perencanaan, dan penyediaan obat difasilitas pelayanan. Dengan daftar Addendum pertama Formularium Nasional maka pasien Prolanis akan mendapatkan obat terpilih yang tepat, bekhasiat, bermutu, aman dan terjangkau.

Dari hasil penelitian ini menunjukkan bahwa perencanaan, diapotek Sana Farma Makassar dari hasil data 2018 dan data 2019 terdapat perbedaan, karena dilihat dari hasil Analisis ABC pemakaian data tahun 2018 menunjukkan obat yang masuk kategori A sebanyak 218.998 yaitu Vitamin B12, Vitamin B1, Vitamin B6, Metformin $500 \mathrm{mg}$, Amlodipin $5 \mathrm{mg}$, kategori B sebanyak 86.939 yaitu 
Amlodipin $10 \mathrm{mg}$, Simvastatin $20 \mathrm{mg}$, Simvastatin $10 \mathrm{mg}$, Aspilet/miniaspi $80 \mathrm{mg}$, Glimepiride $2 \mathrm{mg}$ dan lain-lain dan kategori $\mathrm{C}$ sebanyak 36.377 yaitu Gliklazid $80 \mathrm{mg}$, Captopril $25 \mathrm{mg}$, Nitrokaf retard $2,5 \mathrm{mg}$, Furosemide $40 \mathrm{mg}$, Clopidogrel $75 \mathrm{mg}$ dan lainlain.Sedangkan tahun 2019 yang masuk kategori A sebanyak 216.312 yaitu Vitamin B12, Vitamin B1, Vitamin B6, Metformin $500 \mathrm{mg}$, Amlodipin 5 mg, kategori B sebanyak 84.635 yaitu Amlodipin $10 \mathrm{mg}$, Simvastatin $20 \mathrm{mg}$, Simvastatin $10 \mathrm{mg}$, Glimepiride $2 \mathrm{mg}$, Candesartan $8 \mathrm{mg}$, dan lain-lain dan kategori C sebanyak 34.807 yaitu Nitrokaf retard $2,5 \mathrm{mg}$, Concor 2,5 mg, Candesartan $16 \mathrm{mg}$, Adalat oros $30 \mathrm{mg}$, Acarbose 50mg dan lain-lain. Sehingga terdapat perbedaan dimana jumlah pemakaian obat Prolanis pasien BPJS kesehatan di Apotek Sana Farma Makassar tahun 2018 dan tahun 2019 terjadi peningkatan dan penurunan yaitu pada tahun 2018 obat yang masuk kategori A sebanyak 63,97\% sedangkan tahun 2019 sebanyak 64,41\%, pada tahun 2019 terjadi peningkatan $0,44 \%$. Yang masuk kategori B pada tahun 2018 sebanyak 25,39\% sedangkan tahun 2019 sebanyak 25,21\% pada tahun 2019 terjadi penurunan sebanyak $0.18 \%$. dan yang masuk kategori C pada tahun 2018 sebanyak 10,62\% sedangkan pada tahun 2019 sebanyak 10,36\% terjadi penurunan pada tahun 2019 sebanyak $0,26 \%$.

Apotek Sana Farma Makassar melakukan pengadaan obat Prolanis BPJS 1-2 bulan dan yang memesan obat Apoteker Sana Farma sendiri.Apotek Sana Farma mengharapkan dengan waktu pengadaan obat Prolanis yang dilakukan 1-2 bulan dapat mengurangi terjadinya penumpukan dan penyimpanan obat dalam waktu lama. Dan untuk memenuhi semua jumlah dan jenis obat yang dibutuhan tergantung dari pembayaran BPJS yang telah disepakati. Untuk pengadaan obat Prolanis Apotek Sana Farma membeli dengan cara manual e-catalog, dan apabila Apotek Sana Farma tidak dapat membeli obat Prolanis dengan cara manual e-catalog, Apotek Sana Farma akan mencari harga obat dengan kandungan yang sama yang mendekati harga e-catalog. Hal ini berarti bahwa pengadaan obat Prolanis di Apotek Sana Farma disesuaikan dengan jumlah resep yang masuk.Sabaiknya Apotek Sana Farma menggunakan metode konsumsi.Keunggulan metode ini yaitu memperoleh data yang akurat, metode paling mudah, tidak memerlukan data penyakit maupun standar pengobatan. Jika data konsumsi lengkap pola penulisan tidak berubah dan kebutuhan relatif konstan maka kemungkinan kekurangan atau kelebihan obat sangat kecil. Kekurangannya antara lain tidak dapat untuk mengkaji penggunaan obat dalam perbaikan penulisan resep, kekurangan dan kelebihan obat sulit diandalkan, tidak memerlukan pencatatan data morbiditas yang baik.

Apotek Sana Farma Makassar melakukan penerimaan obat Prolanis yang diserahkan kepada Asisten Apoteker (AA). Untuk setiap obat masuk dilakukan pemeriksaan fisik dan faktur seperti jumlah obat, expired date, nomor batch, pemeriksaan harga ( $e$ catalog), tanda tangan, stempel dan tanggal, tujuannya untuk meningkatkan kepuasan Apotek Sana Farma dalam melakukan pemesanan barang di distributor/PBF (Mendrofa \& Chriswardani, 2016). Apotek Sana Farma Makassar melakukan penyimpanan obat digudang dengan melakukan pemeriksaan ulang seperti jumlah obat, nomor batch, dan expired date. Penyimpanan obat berdasarkan sistem FEFO DAN FIFO dan obat sesuai sediaan, secara alfabetis, suhu ruangan sesuai aturan, membukukan faktur dan melakukan pencatatan kartu stok obat. Pencatatan keluar masuknya obat di gudang merupakan hal yang perlu dilakukan, dalam pencatatan keluar masuknya obat digudang Apotek Sana Farma dilakukan oleh masingmasing penanggung jawab.Tujuan penyimpanan obat Prolanis sesuai dengan SOP Apotek Sana Farma agar dapat bertanggung jawab dalam mempertahakan mutu dan kualitas obat dalam penyimpanan.

Apotek Sana Farma Makassar melakukan pendistribusian obat Prolanis BPJS dengan 2 Metode yaitu metode pelayanan langsung kepasien, misalnya resep masuk kemudian dilakukan pemeriksaan kelengkapan resep, diberi nomor antrian, kemudian Apoteker/AA melakukan persiapan penyediaan obat sesuai resep. Sedangkan metode pendistribusian ke Klinik, Puskesmas, dan Dokter keluarga yang bekerja sama dengan BPJS, misalnya resep dikirim melalui via telpon, SMS, WA dan dijemput. Cara pelayanannya yaitu Apoteker/AA melakukan pemeriksaan kelengkapan resep, diberi nomor resep, dan melakukan persiapan penyediaan obat sesuai resep.Obat Prolanis sudah diberi sesuai standar yang telah ditetapkan oleh BPJS seperti pasien yang baru menggunakan obat insulin harus melampirkan hasil lab seperti (Hbalc), pasien yang baru menggunakan obat jantung yang harus melampirkan hasil lab (Egfr/Egfl).

Pengendalian obat Prolanis BPJS apabila terjadi kekosongan obat, Apotek Sana Farma akan membeli obat yang sama dengan kandungannya dan melakukan negosiasi 
sehingga mendapatkan obat dengan harga sama sesuai ketentuan dari Apotek Sana Farma. Apotek Sana Farma Makassar melakukan pelaporan seperti berita acara pemusnahan, verifikasi resep kepihak BPJS dan stok opname setiap akhir bulan sekali untuk diarsip di Apotek Sana Farma sebagai bukti bahwa telah dilakukan pelaporan, beserta dengan pengecekan Expired Date. Dan untuk obat Prolanis memiliki kartu stok tersendiri untuk menghindari kekosongan obat di gudang serta memudahkan pengecekan keluar masuknya obat.

Apotek Sana Farma Makassar belum pernah melakukan pemusnahan obat Prolanis BPJS dikarenakan distribusi obat Prolanis sangat lancar, sehingga tidak ada obat yang akan dimusnahkan.

\section{KESIMPULAN}

Obat yang masuk dalam perencanaan ditahun 2018-2019 jumlah dan jenisnya hampir sama. Untuk memenuhi kebutuhan dalam proses pengadaan obat Prolanis, tergantung dari pembayaran BPJS yang telah di sepakati. Proses penerimaan obat Prolanis sudah memenuhi SOP di Apotek Sana Farma Makassar. Penyimpanan obat Prolanis berdasarkan sistem FEFO dan FIFO serta pengaturan suhu. Proses pendistribusian obat Prolanis sudah memenuhi standar yang telah ditetapkan oleh BPJS dan SOP Apotek Sana Farma Makassar. Proses pengendalian obat Prolanis di Apotek Sana Farma Makassar dilakukan berita acara pemusnahan dan verifikasi resep dari pihak BPJS. Pemusnahan di Apotek Sana Farma Makassar dilakukan sesuai dengan aturan yang berlaku.

\section{SARAN}

Untuk perencanaan obat Prolanis Apotek Sana Farma sebaiknya menggunakan metode komsumsi dengan Analisis ABC, agar tidak terjadi kekosongan ataupun stagnant obat.

\section{UCAPAN TERIMA KASIH}

Kami mengucapkan terima kasih kepada seluruh pimpinan Stikes Pelamonia Kesdam VII/Wirabuana, terkhusus Ibu Mayor CKM (K) Veronica MD., S.Si., M.Kes., Apt dan Dr. Rusli, SP.FRS., Apt, serta pimpinan staf Apotek Sana Farma Makassar.

\section{DAFTAR PUSTAKA}

Atmini, K., GandjaR, I., \& Purnomo, A. (2011). Analisis aplikasi standar pelayanan Kefarmasian di Apotek kota Yogyakarta.

Putri, B., \& Kartika, L. (2017). Pengaruh Kualitas Pelayanan BPJS Kesehatan Terhadap Kepuasan pengguna Perspektif Dokter Rumah Sakit Hermina Bogor.

Edris, M., \& Lusianti, D. (2016). Analisis Operasional BPJS Kesehatan terhadap prinsip Ekonomi Syariah.

Rosdiana, A., \& Rahardjo, B. S. (2017). Implementasi Program Pengelolaan Penyakit Kronis (PROLANIS).

Lanathasya, \& Nadjib, M. (2015). Gambar stock Out Obat Program Rujuk Balik bagi Peserta JKN di BPJS Kesehatan Jakarta Pusat Pada Agustus 201.

Mulyagustina, Wiedyaningsih, C., \& Kristina, S. A. (2017). Implemetasi Standar Pelayanan Kefarmasian di Apotek Kota Jambi.

Kusmini, Satibi, \& Suryawati, S. (2016). Evaluasi Pelaksanaan E-Purchasing Obat pada Dinas Kesehatan Kabupaten/Kota di Jawa Tengah Tahun 2015. 